\title{
Marine microbial natural products: the evolution of a new field of science
}

\author{
William (Bill) Fenical ${ }^{1}$
}

Received: 17 May 2020 / Accepted: 21 May 2020 / Published online: 27 July 2020

(C) The Author(s), under exclusive licence to the Japan Antibiotics Research Association 2020

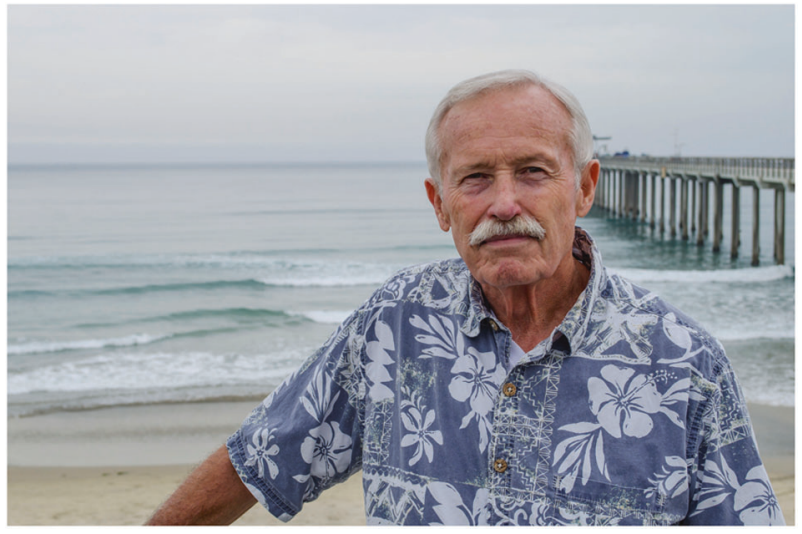

Allow me to begin by expressing my sincere thanks to the editors of the Journal of Antibiotics for granting me this very special place in the history of the journal. Since the beginning of my career at the Scripps Institution of Oceanography, I have had the opportunity to be among the first few to explore marine natural products chemistry. This was exciting because almost everything we examined was new and yielded novel metabolites. I am pleased to be able to trace here the evolution of my involvement in marine microbial natural products chemistry over the period 1990-2020.

During the course of my scientific adventure, many colleagues and collaborators, too many to cite here, have made profound contributions to my research program. I was very lucky to have such excellent students, postdocs, and visitors over the years. There is one individual, however, who contributed much more than anyone else. This is Professor Paul Jensen at the Scripps Institution of

William (Bill) Fenical

wfenical@ucsd.edu

1 Scripps Institution of Oceanography, University of California, San Diego, La Jolla, CA 92093-0204, USA
Oceanography. Paul and I have collaborated since the early 1990s, and it was with Paul's deep knowledge and skills in basic microbiology that we undertook the challenge of exploring the microbes in the oceans as a source of antibiotics and antitumor agents.

In this editorial, I am taking the opportunity to review a few of our discoveries from marine bacteria. It will be anything but comprehensive, and I apologize to my former students and colleagues for leaving out your important work. The point of this editorial is to mention a few highlights about our studies of marine microorganisms, from the beginning when we really did not know what we were doing, to the current time in which microbiology has become much more sophisticated and, to a growing extent, relies on genomic information to guide and predict where interesting molecules might be produced. My career has spanned the more fundamental early days and has moved to embrace these new tools.

My scientific training (Ph.D.) was in synthetic organic chemistry, but I always had a personal fascination with the ocean and its inhabitants. During my M.S. research at San Jose State University, I worked alongside a student who was isolating the red pigments from abalone shells. He and I would travel to the California coast and collect abalone for his work, then grind the outer shell pigment layer and extract the pigments. This experience was likely the beginning of my interest in marine natural products as I realized how little we knew about what is being produced by marine life.

After my Ph.D., I was fortunate to have a temporary research position with Professor Jim Sims at UC-Riverside. Jim was a trained natural products chemist who had worked with the renown chemist Albert Eschenmosher at the ETH in Zürich [1]. Jim had been exposed to many new tools of structure elucidation and natural products, and he was generous in teaching me all he had learned. It turned out that my background in synthesis was a perfect foundation for what would come next. During this period, Jim and I 


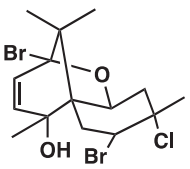

1, Pacifenol

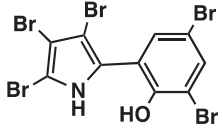

2, Pentabromopseudilin
Fig. 1 Halogenated natural products from algae (1) and a unique marine bacterium (2)

studied the chemistry of marine algae and published several papers, including one describing the unique sesquiterpene pacifenol (1, Fig. 1) [2]. This compound was the first to contain both chlorine and bromine, elements with more characteristics of industrial chemicals. I remember my work being criticized at a local ACS meeting since some thought pacifenol had to be a man-made pesticide. It shows you how far marine natural products have come in the past 40 years.

In 1973, I was fortunate to move to a nontenured research position at the Scripps Institution of Oceanography, the school of oceanography at UC-San Diego that dates back to 1900 . This move allowed me to enrich my background in marine biology and to embark on a long career in which I worked in the 70 s and 80 s on the natural products of a host of plants and invertebrate animals [3]. As the field of marine natural products matured during the 1980 s, it was clear to me that a massive area of potential science studies of the chemistry of marine microorganisms had not been undertaken. I wondered, why?

In the 1990s, Paul Jensen and I explored the literature in this area and tried to understand the lack of research reported. It seemed obvious to us that bacteria, fungi, and related marine microorganisms of chemical interest should be found in the sea. But where are they found, and of even greater concern, are marine taxa related to those terrestrial forms that had provided such a rich and profound arsenal of antibiotics and antitumor agents? While we were examining this concept, there was a preponderance of negative comments regarding the presence of microbes in the sea. Many researchers said that marine bacteria could not be cultured (above perhaps $0.5 \%$; more on this later). Others were even more negative in making conclusions that the actinomycete bacteria, perhaps the most prolific producers of bioactive metabolites, were not unique in the ocean, but simply terrestrial strains rinsed into the sea [4]. This was the most discouraging comment of all.

In the first few years of my career at SIO, I was fortunate to meet Professor Claude E. ZoBell, a visionary microbiologist now considered the "Father of Marine Microbiology" [5]. ZoBell had spent his entire career trying to convince the microbiology community that the microbes he was isolating, including deep ocean barophilic bacteria, were unique. He too was facing the criticism of the community that was very focused on studies of the soil.
Although I remember talking to him about my interests in natural products chemistry, this was not his area and he had little to contribute.

While there was very little marine microbial chemistry reported in the literature, a profound discovery of a metabolite, pentabromopseudilin (2, Fig. 1), had been reported in 1966 by Burkholder et al. from Columbia University. This exceptional finding piqued our interest and thus we moved forward [6]. Paul Burkholder was a visionary who examined the microorganisms from numerous mostly tropical marine samples. While in Puerto Rico, he isolated a Gmbacterium, later labeled Pseudomonas bromoutilis, from the surface of the marine seagrass Thalassia testudinum. In subsequent culture studies Burkholder showed this strain to produce 2 , a molecule that is more than $70 \%$ bromine by weight. At that time, naturally brominated organic molecules were either rare or unknown. This foundational discovery carried us forward, but still with the apprehension that our work would be naive and unproductive (as some had predicted).

In order to educate ourselves, we consulted with a host of industrial microbiologists who had extensive knowledge of microbial isolation and culture methods. We had little training in the practical mechanics of industrial microbial discovery.

With background information in hand, Paul and I set out to see what was out there! We did not know where major bacterial populations could be found, so we sampled everywhere: seawater, sediments, and animate and inanimate surfaces. We were fortunate to have access to research vessels as part of the US National Science Foundation's University-National Oceanographic Laboratory program. With that opportunity we sampled in the tropical Atlantic Ocean, as well as numerous international environments.

We realized that only a very limited area of the ocean, and limited depths, could be easily sampled using SCUBA. Consequently, we evaluated the tools oceanographers use for deep sea sediment sampling, generally from large research vessels. We miniaturized coring devices and used small sediment "snappers" that could easily be deployed and then retrieved from small boats using electric reels. With these samplers, we were able to effectively sample to depths of about $2000 \mathrm{~m}$. Deeper ocean samples turned out to be complex and to vary in their bacterial composition on a very small spatial scale. Different bacteria could be cultured from samples taken only $10 \mathrm{~m}$ apart. In retrospect these yielded some of our most interesting and prolific results. Still, we did not know if we were isolating any significant percentage of what was there.

Cultivation, in the beginning, was hit or miss at best. We explored numerous culture media and methods to see what would work best. We incorporated various "marine nutrients" (seaweed powder, fish paste, chitin, agar, mannitol, 


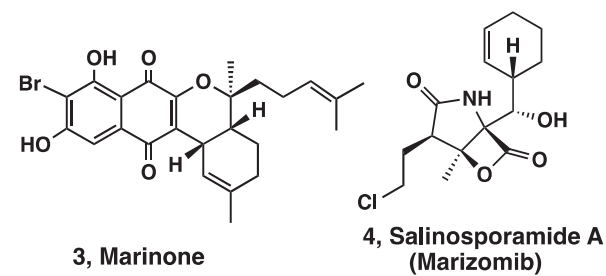

Fig. 2 Two halogenated metabolites from obligate marine bacteria. Marizomib is in Phase III clinical trials for glioblastoma brain cancer

inter alia) into culture media to see what effect this had on strain isolation diversity. Because it had been stated that actinomycetes were not unique, but were terrestrial bacteria whose spores were washed into the sea in rivers and rainwater, we undertook a study looking at the actinomycete taxa in the sediments as a function of distance from shore [7]. The results of this study, undertaken in the Caribbean, were highly encouraging and showed that as we sampled into deeper water, typical soil streptomycetes diminished in favor of unknown actinomycete taxa (the actinoplanetes). At $30 \mathrm{~m}$ depth, the sediments were dominated by the presence of non-streptomycete bacteria. Furthermore, of the near-shore streptomycetes isolated, and assumed to be soil derived, more than half grew better in seawater-based media. Perfect! We had started to generate sufficient information to justify delving deeper.

In the early years of our work, we began to see streptomycetes that were producing unique metabolites and illustrating a requirement for seawater as the foundation of their culture media. One such example was Streptomyces sp. CNB632, a seawater-requiring strain collected in a shallow mangrove channel in the Bahamas. In culture, this strain produced a series of meroterpenoids exemplified by Marinone (3, Fig. 2) [8]. This compound, reported in 1992, is a hybrid between an aromatic polyketide linked to a cyclized sesquiterpenoid. The presence of bromine was exciting to see. Once again, this molecule illustrated the availability of the halogens as building blocks in ordinary seawater and further provided evidence that true marine streptomycetes existed.

One of our most important early discoveries was that of a novel, obligate marine actinomycete that was assigned as the genus name Salinispora [9]. This new taxon was discovered by Paul Jensen and graduate student Tracy Mincer using fine-tuned 16S rDNA sequencing methods. Sequence data showed the new genus was closely related to Micromonospora (Micromonosporaceae), but because we examined many strains (perhaps up to 100 isolates), we were able to see the fine sequence variations that differentiated three species, S. tropica, S. arenicola, and S. pacifica (and Paul later recognized six more) [10].

We began to isolate a larger number of Salinispora, in particular S. tropica, which contrary to microbial distribution theory appears to be limited in distribution to the tropical Atlantic Ocean. One specific isolate of S. tropica, our strain CNB392, was immediately recognized to produce a highly cytotoxic compound against a diverse group of cancer cell lines. Purification yielded a unique beta-lactone, salinosporamide A (4, "Sal A," Fig. 2), that also contained a gamma-lactam and primary chlorine [11]. Based on the nM potency of this agent and its novel composition related to the proteasome inhibitor omuralide, we began to realize that marine microbes are a great source for the discovery of anticancer agents. Indeed, Sal A (4) was a potent inhibitor of the $20 \mathrm{~S}$ proteasome.

During this same period, we approached the US National Cancer Institute proposing to explore marine bacteria for the development of new cancer treatments. They were enthusiastic about the potential of natural products in treating the disease, so they began to fund our efforts as well as to generate new programs in which academics collaborated with pharmaceutical industries. These programs allowed us to have access to a greater diversity of in vitro bioassays and in vivo experiments, especially as part of a collaboration with researchers at Bristol-Myers Squibb.

As time passed and we had isolated a diversity of highly cytotoxic agents of possible use in treating cancer, we pondered how we would ever develop any of our findings. Again, stepping into the unknown, our solution was to be the founders of Nereus Pharmaceuticals in La Jolla. Nereus is the god of the Aegean Sea, an appropriate name. Over the next few years, our program contributed to the rapid growth of Nereus to more than 50 researchers. Their focus was almost entirely on cancer, so they licensed several of our discovered molecules, but they clearly had a greater focus on the development of Sal A. Nereus licensed Sal A from UC-San Diego and began a long and often tedious preclinical development program. They confirmed that the compound had potent activity against all three of the proteasome degradation enzymes, and in consideration of the targets for this type of drug, began to focus on multiple myeloma as a therapeutic target. As with any drug, there were several years of ups and downs, including defining toxicity and the best way to administer the drug. But after years of intense evaluation, Sal A was approved for a Phase I clinical trial under the name marizomib [12]. Marizomib has experienced a long and complex pathway for development. Nereus, on their closing, passed the drug on to another company for development. That company was ultimately bought by Bristol-Myers Squibb, which has carried the drug along to Phase III evaluation. Along the way, marizomib was observed to pass through the blood-brain Barrier. This led to the current trials against glioblastoma, a brain tumor and one of the most dangerous of all cancers. 

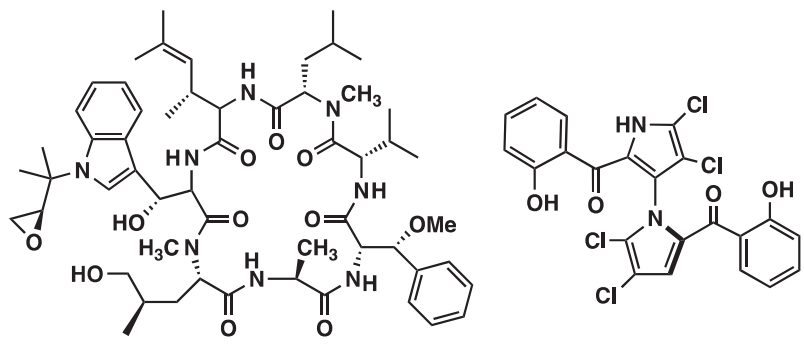

5, Cyclomarin A

6, Marinopyrrole A

Fig. 3 Two antibiotics isolated from marine-derived and obligate marine bacteria

Paul Jensen's group has sequenced the genomes of over 115 Salinispora isolates illustrating the presence of large numbers of diverse biosynthetic pathways [13]. Chemical studies have continued on an international basis yielding hundreds of novel metabolites, including alkaloids, polyketide macrolides, cycloaromatization products of enediynes, depsipeptides, aromatic quinones and glycosylated analogs, and macrolactams, to name a few. The biosynthetic diversity of these molecules clearly demonstrates that the genus Salinispora is a rich resource for drug discovery and a model organism for a host of important evolutionary studies [14].

While the availability of funding created strong programs for the treatment of cancer, we tried to focus part of our research on the important need for new anti-inflammatory agents and antibiotics. Marine bacteria most certainly had to be a good source for antibiotics when one considers the precedent set in the $60+$ years of soil bacteria exploration. Screening for antibacterial activities is a relatively simple process, but the subsequent steps in development were outside our abilities. Further, with antibiotic discovery and development falling into disfavor, we have had difficulties in advancing our discoveries.

One of our first anti-inflammatory agents discovered was the cyclic peptide cyclomarin A (5, Fig. 3), produced by a Streptomyces strain collected close to our lab in California [15]. The structure of this compound, generated by X-ray crystallography, was kindly provided by my long-term collaborator Jon Clardy (Harvard Medical School). As cyclomarin A showed interesting structural features, the biosynthetic origins of these molecules were examined in detail by my Scripps colleague Brad Moore [16]. We did not recognize the antibacterial features of this compound. In subsequent reports, potent antimalarial and anti-Mycobacterium tuberculosis activity, as well as the putative target as the $\mathrm{N}$-terminal domain of $\mathrm{ClpCl}$, has been fully described. Obviously, this was a revelation suggesting we focus further work on antibiotics [17].

In the recent past, we have isolated a variety of new antibacterial agents, some useful and others simply too

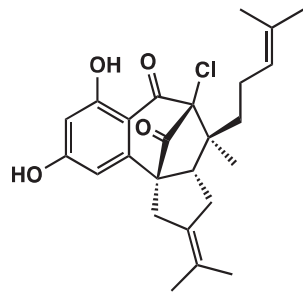

7, Merochlorin A

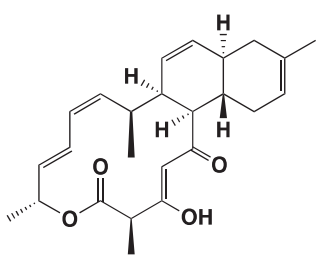

8, Anthracimycin
Fig. 4 Two structurally unique antibacterial metabolites isolated from marine bacteria

toxic. The isolation of the marinopyrroles, as exemplified by marinopyrrole A (6, Fig. 3), illustrated once more that apparently uniquely marine-adapted strains of streptomycetes could be found in the oceans. Streptomyces strain CNQ418, which showed poor 16S rDNA sequence comparisons to related type strains, also showed a requirement for cultivation using seawater [18]. Marinopyrrole A is a unique $M$-(-)-atropo-isomer with restricted rotation around the central $\mathrm{N}-\mathrm{C}$ bond. In testing against a panel of $\mathrm{Gm}+$ bacterial pathogens, marinopyrrole A showed consistent MIC values of under $1 \mu \mathrm{g} / \mathrm{mL}$ [19]. Unfortunately, it was also discovered that the compound reacted with serum rendering it a useless clinical candidate. It was ultimately found that nucleophiles were capable of displacing the chlorine substituent on one of the pyrrole rings [20].

Another unusual example of a unique marine antibacterial agent is merochlorin A (7, Fig. 4) [21]. This compound, produced by a shallow water Streptomyces strain (CNH189), is a meroterpenoid composed of apparent terpenoid and polyketide components. The structure of merochlorin A is unprecedented among the meroterpenoids as the terpenoid backbone is rearranged in unprecedented ways. This metabolite shows significant activity against a variety of human pathogens with typical $\mathrm{Gm}+$ pathogen values in the $1-2 \mu \mathrm{g} / \mathrm{mL}$ range. More interesting is that the compound shows potent inhibition of Clostridium difficile (BI) at $0.15 \mu \mathrm{g} / \mathrm{mL}$, a bacterium well known to cause severe gastric distress [22].

Along with merochlorin A are a host of analogous highly rearranged meroterpenoids of unique and complex biosynthetic origins [23]. These merochlorin analogs are the products of an unprecedented branched sesquiterpene precursor complexing with the aromatic polyketide. The biosynthesis of these compounds was well studied by my colleague Brad Moore, who has expressed the relevant biosynthetic enzymes and demonstrated an elegant one-pot enzymatic synthesis of merochlorins A and B [23].

Anthracimycin (8, Fig. 4) is an example of a potent antibacterial agent produced by a Streptomyces strain (CNH365). Our studies showed that this antibiotic possessed the properties that could be used in drug development. This strain was isolated from ordinary beach sand 
collected north of us in Southern California. Anthracimycin, the structure of which was assigned by X-ray methods, is a potent inhibitor of the anthrax pathogen Bacillus anthracis, with MIC values of $0.031 \mu \mathrm{g} / \mathrm{mL}$ [24]. Anthracimycin is a structurally unique compound that does not compare with any known antibacterial natural products or synthetic compounds. Anthracimycin is also active against various MRSA strains within a similar dose range [25]. Given that this is a new carbon skeleton with significant antibacterial properties, I would have thought there might be developmental interest. Perhaps there has been interest that I am not aware of, but I have not been asked for a single sample. This is likely due to the fact that anthracimycin is inactive toward $\mathrm{Gm}-$ pathogens that represent a much bigger challenge in controlling drug-resistant infectious diseases.

Along the way, we tried to assess if we were in fact isolating a significant percentage of the bacteria present in our samples. We did feel that we had good methods for the isolation of actinomycetes and actinobacteria in general, but we constantly remembered the discouraging critique that we could not cultivate in excess of $0.5 \%$ of what was there. The concept of poor cultivation efficacy goes back to the "Great Plate Count Anomaly" coined by Staley and Konopka [26]. They described the difference between the numbers of cells from natural environments that formed colonies on agar media and the numbers countable by microscopic examination [26]. There is truth to this observation, as under most circumstances colony formation on agar surfaces does reflect this limitation. However, over the recent past a host of scientific advances in microbial isolation methods has appeared (too many to be discussed here).

If one looks over the $16 \mathrm{~S}$ rDNA-generated databases it is clear that there are a very large number of bacteria that form the "great uncultured majority." This is certainly true, and perhaps more true for marine bacteria. Some consider these unculturable (uncultivable), but that is clearly not the case. We had an interest in this subject and decided to explore some simple but generally unused methods to assess whether we could access these uncultured majority. To approach this issue, we employed two nontypical methods: the use of very low nutrient media and the time to colony formation on agar surfaces [27]. Using zero-added nutrients to agar, we found that a significant number of oligotrophic bacteria could be observed. More importantly, we undertook a time course for isolation that involved monitoring the isolation plates over very long incubation periods from 1 to 6 months. To our surprise, we began to see colony formation after long periods of incubation. This experiment generated 20 strains of obligate $\mathrm{Gm}$ - marine bacteria that by $16 \mathrm{~S}$ rDNA sequencing were directly within a group of uncultured bacteria that had only been seen by culture independent methods (eDNA sequencing) [27].

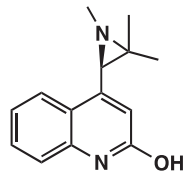

9, Alkaloid

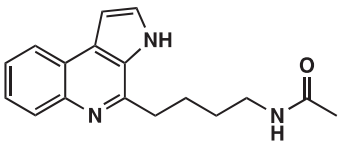

10, Alkaloid
Fig. 5 Examples of new quinoline alkaloids isolated from marine bacteria cultured from the "great uncultured majority"

All 20 strains fell within the uncultured majority, and many were so distant from their nearest neighbors that they were anticipated to be new genera, families, and possibly even orders. Two of the strains we described were Catalinamonas alkaloidigena and Mooreia alkaloidigena, species that appear to represent new families within order Cytophagales. As evident from their species names, these strains are chemically rich and produce alkaloids representing four different carbon skeletons (two examples are $\mathbf{9}$ and 10, Fig. 5). We gained several new ideas from this study. First, it may take very long periods of time for bacterial strains to adjust to an agar surface and grow. Also, in many cases the use of extremely low nutrients is essential as it mimics the natural nutrient concentrations in ocean waters. Second, we found that once isolated in pure culture, these strains would grow quite well with common nutrients. The lesson in this study is that we may be using inappropriate culture conditions, most of which are set in stone by early microbiologists. Importantly, this study illuminated at least two new families of $\mathrm{Gm}$ - bacteria capable of the production of alkaloidal natural products. The question is, have we been missing many exciting marine bacteria because we used older microbiological methods? I think this must be true.

I acknowledge that the majority of our work, so far, has been to follow history to focus much of our efforts on the chemically rich actinomycetes. This was appropriate and productive, but I am sure that the breadth of marine microbial discovery is more expansive. Two other recent studies have likely also illustrated this. In an investigation of the $\mathrm{Gm}-$ marine-derived bacterium Tistrella mobilis, we [28] and Tsukimoto et al. in Japan [29] observed the production of the ascidian metabolite didemnin B (11, Fig. 6). This potently cytotoxic metabolite was famous for being the first marine natural product to enter clinical trials for cancer. The compound was originally isolated from the Caribbean ascidian Trididemnum solidum, but its origin in bacterial biosynthesis was not considered. While examining the growth time course of $T$. mobilis colonies on agar using imaging mass spectrometry, we observed that didemnin B was not the first formed natural product, but was produced by extracellular hydrolysis of a potentially less cytotoxic precursor.

Also illustrating the importance of marine $\mathrm{Gm}-$ bacteria was our investigation of the marine bacterium 
Fig. 6 Two PKS-NRPS derived cyclic peptides isolated from $\mathrm{Gm}$ - marine bacteria. Didemnin $\mathrm{B}$ was the first marine compound to enter clinical trials

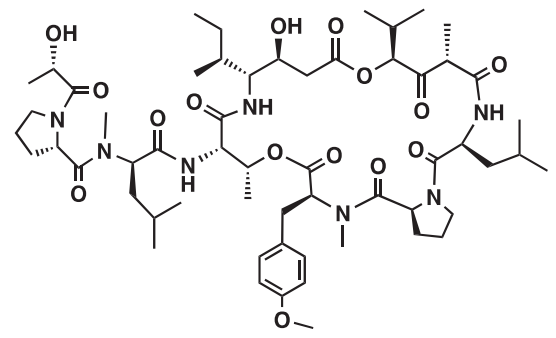

11, Didemnin B

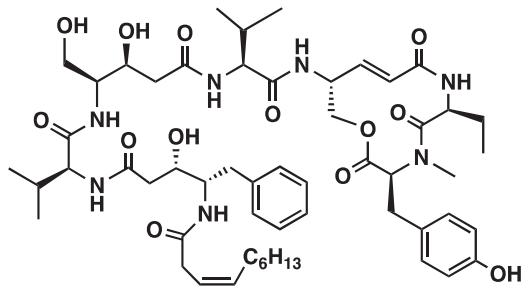

12, Thalassospiramide $B$
Thalassospira sp. (strain CNJ-328). This strain was found to produce two immunosuppressive peptides, the thalassospiramides A and B (12, Fig. 6) of unique biosynthetic origin [30]. The Moore lab, in their investigation of the biosynthetic origin of these metabolites, has also found that various Tistrella and Thalassospira strains produce an expanded diversity of thalassospiramide congeners [31].

There are a few conclusions to this story. First and foremost, marine bacteria are without question a solid and exciting resource for the isolation of novel natural products for drug discovery. Taxonomically unique, marine actinomycetes are present in marine sediments and on and within marine plants and animals. Further, strong evidence exists to show that the members of the common soil taxon Streptomyces are, in fact, adapted to life in the sea. The investigations mentioned above, which involved unicellular $\mathrm{Gm}$ - marine bacteria, show that we are likely being too myopic in selecting the taxa of marine bacteria for study. As we move even more deeply into using genomic and bioinformatics tools, it is clear that marine bacteria will enjoy a prominent position in future studies.

Then there is the exciting topic of obligate marine symbiotic bacteria, especially those that are exclusively found within invertebrate tissues. To date these bacteria have been difficult to cultivate. We have dabbled in this area, looking at the epiphytic bacteria that protect crustaceans from fungal infection [32], but this is a massive and exciting area that has required complex molecular tools to even describe. Fully defining symbiotic marine bacteria, and eventually cultivating them and isolating their metabolites, must be considered one of the most exciting and rewarding future areas in marine microbial natural products research [33].

Finally, let me offer my sincere thanks to Dr. Jim McAlpine, and Professor Hiroshi Tomoda, who worked tirelessly to organize this dedicated issue, and to the contributing authors, many of whom are my friends and colleagues, who made this issue possible.

\section{Compliance with ethical standards}

Conflict of interest The authors declare that they have no conflict of interest.
Publisher's note Springer Nature remains neutral with regard to jurisdictional claims in published maps and institutional affiliations.

\section{References}

1. Wikipedia. Albert Eschenmoser. 2020. https://en.wikipedia.org/w iki/Albert Eschenmoser.

2. Sims JJ, Fenical W, Wing RM, Radlick P. Pacifenol, a rare sesquiterpene containing bromine and chlorine from the red alga, Laurencia pacifica. J Am Chem Soc. 1971;93:3774-5.

3. Scripps Institution of Oceanography, University of California, San Diego. Profiles. 2020. https://wfenical.scrippsprofiles.ucsd.edu.

4. Goodfellow M, Haynes JA. Actinomycetes in marine sediments. In: Ortiz-Ortiz L, Bojalil LF, Yakoleff V, editors. Biological, biochemical and biomedical aspects of actinomycetes. Academic Press; 1984. p. 453-72.

5. Encyclopedia.com. Zobell, Claude Ephraim (1904-1989). 2020. https://www.encyclopedia.com/science/encyclopedias-almanacstranscripts-and-maps/zobell-claude-ephraim-1904-1989.

6. Burkholder PR, Pfister RM, Leitz FH. Production of a pyrrole antibiotic by a marine bacterium. Appl Microbiol. 1966;14:649.

7. Jensen PR, Dwight R, Fenical W. Distribution of actinomycetes in near-shore tropical marine sediments. Appl Environ Microbiol. 1991;57:1102-8

8. Pathirana C, Jensen PR, Fenical W. Marinone and debromomarinone: antibiotic sesquiterpenoid naphthoquinones of a new structure class from a marine bacterium. Tetrahedron Lett. 1992;33:7663-6

9. Mincer TJ, Jensen PR, Kauffman CA, Fenical W. Widespread and persistent populations of a major new marine actinomycete taxon in ocean sediments. Appl Environ Microbiol. 2002;68:5005-11.

10. Maldonado LA, Fenical W, Jensen PR, Kauffman CA, Mincer TJ, Ward AC, et al. Salinispora arenicola gen. nov., sp. nov. and Salinispora tropica sp. nov., obligate marine actinomycetes belonging to the family Micromonosporaceae. Int J Syst Evol Microbiol. 2005;55:1759-66.

11. Feling RH, Buchanan GO, Mincer TJ, Kauffman CA, Jensen PR, Fenical W. Salinosporamide A: a highly cytotoxic proteasome inhibitor from a novel microbial source, a marine bacterium of the new genus Salinospora. Angew Chem Int Ed. 2003;42:355-7.

12. Potts BC, Albitar MX, Anderson KC, Baritaki S, Berkers C, Bonavida B, et al. Marizomib, a proteasome inhibitor for all seasons: preclinical profile and a framework for clinical trials. Curr Cancer Drug Targets. 2011;11:254-84.

13. Millán-Aguiñaga N, Chavarria KL, Ugalde JA, Letzel A-C, Rouse GW. Phylogenomic insight into Salinispora (Bacteria, Actinobacteria) species designations. Sci Rep. 2017;7:3564.

14. Jensen PR, Moore BS, Fenical W. The marine actinomycete genus Salinispora: a model organism for secondary metabolite discovery. Nat Prod Rep. 2015;32:738. 
15. Renner MK, Shen YC, Cheng XC, Jensen PR, Frankmoelle W, Kauffman CA, et al. Cyclomarins A-C, new antiinflammatory cyclic peptides produced by a marine bacterium (Streptomyces sp.). J Am Chem Soc. 1999;121:11273-6.

16. Schultz AW, Oh D-C, Carney JR, Williamson RT, Udwary DW, Jensen PR, et al. Biosynthesis and structures of cyclomarins and cyclomarazines, prenylated cyclic peptides of marine actinobacterial origin. J Am Chem Soc. 2008;130:4507-16.

17. Schmitt EK, Riwanto M, Sambandamurthy V, Roggo S, Miault C, Zwingelstein $\mathrm{C}$, et al. The natural product cyclomarin kills Mycobacterium tuberculosis by targeting the $\mathrm{ClpC1}$ subunit of the caseinolytic protease. Angew Chem Int Ed. 2011; 50:5889-91.

18. Hughes CH, Prieto-Davo A, Jensen PR, Fenical W. The marinopyrroles, antibiotics of an unprecedented structure class from a marine Streptomyces sp. Org Lett. 2008;10:629-31.

19. Haste NM, Hughes CC, Tran DN, Fenical W, Jensen PR, Nizet V, et al. Pharmacological properties of the marine natural product marinopyrrole A against methicillin-resistant Staphylococcus aureus. Antimicrob Agents Chemother. 2011;55:3305-12.

20. Hughes CC, Kauffman CA, Jensen PR, Fenical W. Structures, reactivities, and antibiotic properties of the marinopyrroles A-F. J Org Chem. 2010;75:3240-50.

21. Kaysser L, Bernhardt P, Nam S-J, Loesgen S, Ruby JG, SkewesCox P, et al. Merochlorins A-D, cyclic meroterpenoid antibiotics biosynthesized in divergent pathways with vanadium-dependent chloroperoxidases. J Am Chem Soc. 2012;134:11988-91.

22. Sakoulas G, Nam S-J, Loesgen S, Fenical W, Jensen PR, Nizet V, et al. Novel bacterial metabolite merochlorin A demonstrates in vitro activity against multi-drug resistant methicillin-resistant Staphylococcus aureus. PLoS ONE. 2012;7:e29439.

23. Teufel R, Kaysser L, Villaume MT, Diethelm S, Carbullido MK, Baran PS, et al. One-pot enzymatic synthesis of merochlorin A and B. Angew Chem Int Ed Engl. 2014;53:11019-22.
24. Jang KH, Nam S-J, Locke JB, Kauffman CA, Beatty DS, Paul LA, et al. Anthracimycin, a potent anthrax antibiotic from a marine-derived actinomycete. Angew Chem Int Ed Engl. 2013;52:7822-4.

25. Mary E, Hensler ME, Jang K-Y, Thienphrapa W, Vuong L, Tran DN, et al. Anthracimycin activity against contemporary methicillinresistant Staphylococcus aureus. J Antibioti. 2014;67:1-5.

26. Staley JT, Konopka A. Measurement of in situ activities of nonphotosynthetic microorganisms in aquatic and terrestrial habitats. Annu Rev Microbiol. 1985;39:321-46.

27. Choi E-J, Nam S-J, Paul L, Beatty D, Kauffman CA, Jensen PR, et al. Previously uncultured marine bacteria linked to novel alkaloid production. Chem Biol. 2015;22:1270-9.

28. Xu Y, Kersten RD, Nam SJ, Lu L, Al-Suwailem AM, Zheng H, et al. Bacterial biosynthesis and maturation of the didemnin anticancer agents. J Am Chem Soc. 2012;134:8625-32.

29. Tsukimoto M, Nagaoka M, Shishido Y, Fujimoto J, Nishisaka F, Matsumoto S, et al. Bacterial production of the tunicate-derived antitumor cyclic depsipeptide didemnin B. J Nat Prod. 2011;74:2329-31.

30. Oh D-C, Strangman WK, Kauffman CA, Jensen PR, Fenical W. Thalassospiramides A and B, immunosuppressive peptides from the marine bacterium Thalassospira sp. Org Lett. 2007;9:1525-8.

31. Ross AC, Xu Y, Lu L, Kersten RD, Shao Z, Al-Suwailem AM, et al. Biosynthetic multitasking facilitates thalassospiramide structural diversity in marine bacteria. $\mathrm{J}$ Am Chem Soc. 2013;135:1155-62.

32. Gil-Turnes MS, Hay ME, Fenical W. Symbiotic marine bacteria chemically defend crustacean embryos from a pathogenic fungus. Science. 1989;246:116-8.

33. Brinkmann CM, Marker A, Ipek Kurtböke D. An overview on marine sponge-symbiotic bacteria as unexhausted sources for natural product discovery. Diversity. 2017;9:40. 